\title{
Association of Two Angiogenic Genes Polymorphism with Clinical Course and Prognosis of Non-Hodgkin Lymphoma in Egyptian Patients
}

\author{
Dina EL DAHSHAN ${ }^{1}$, Shaymaa SHOLKAMY ${ }^{1}$, Enass AZZAB ${ }^{1}$, \\ Mohamed EL WAKIL ${ }^{2}$, Amr EL SAYED ${ }^{3}$ \\ ${ }^{1}$ Beni-Suef University Faculty of Medicine, Department of Clinical Pathology \\ ${ }^{2}$ Beni-Suef University Faculty of Medicine, Department of Oncology \\ ${ }^{3}$ Beni-Suef University Faculty of Post Graduate Studies for Advanced Science, \\ Department of Biotechnology, Beni-Suef, EGYPT
}

\begin{abstract}
Angiogenesis is a main process that helps in the growth and survival of many haematopoietic neoplasms one of them is non-Hodgkin's lymphomas (NHLs). Both the vascular endothelial growth factor (VEGF) and basic fibroblast growth factor (bFGF), are key initiators of angiogenesis, they can act by direct stimulation of tumour cells or by influencing the surrounding microenvironment. Previous studies suggested that their expression affected the course and progression of the disease. The current study aimed to reveal the relationship between the genotyping of VEGF and bFGF genes and the susceptibility to NHL and its' association with disease course and prognosis. PCR-RFLP technique was used for detection of VEGF (rs3025039), and bFGF (rs308395) mutations in 40 NHL patients and 40 healthy individuals as a control group. Patients carrying the mutant T allele of VEGF gene were more than twice more susceptible to $\mathrm{NHL}(\mathrm{OR}=2.714, \mathrm{p}=0.039)$, and its presence was also significantly higher in patients with $\mathrm{B}$ symptoms $(\mathrm{p}<0.001)$. Moreover, the polymorphic VEGF was significantly higher among patients who did not respond to treatment $(42.1 \%)(p=0.017)$. The presence of the polymorphic bFGF mutant G showed significantly higher susceptibility to aggressive histological subtypes of NHL compared to those with indolent subtypes ( $p=0.010$, OR 17.818), and compared to normal controls ( $p=0.014$, OR 3.818). These findings imply that polymorphism of angiogenic factors such as VEGF and bFGF are related to clinical characteristics and histological subtype of NHL, which showed prognostic significance that might serve as future markers for tailoring treatment and monitoring response in these patients.
\end{abstract}

Keywords; NHL, Angiogenesis, VEGF, bFGF, Gene polymorphism

\section{INTRODUCTION}

Non-Hodgkin's lymphomas (NHLs) are a heterogenous group of lymphoproliferative malignancies having various behaviors, clinical presentations, disease course and prognosis. Many biological and clinical factors affect the clinical course and the treatment decisions. Biological mechanisms influencing to the course of NHL are still not fully understood. ${ }^{1}$
The growth and progression of lymphoma might be augmented by angiogenesis. Both vascular endothelial growth factor (VEGF) and basic fibroblast growth factor (bFGF) are key players in this process. The VEGF is a powerful mediator of angiogenesis both by autocrine stimulation of tumour cells in addition to its paracrine influence on proangiogenic tumour microenvironment. ${ }^{1}$ 
Some studies reported that the VEGF expression reflected the proliferative activity in lymphomas. Because of the heterogeneity of the disease, its variable classifications and different methods of analysis; it is controversial if the enhancement of microvessel density and the proangiogenic factors can be of predictive value for prognosis in NHL. ${ }^{2}$

The human VEGF gene is located on chromosome $6 \mathrm{p} 21.3$ it is formed of 8 exons separated by 7 introns. ${ }^{3}$ Studies have described many different single nucleotide polymorphisms (SNPs) in the VEGF gene. ${ }^{4,5}$ While the human bFGF gene is located on chromosome $4 .{ }^{6}$ Polymorphisms in the promoter region of the bFGF gene can interfere with the binding sites oftranscription factor or may produce new binding sites and, therefore, influence bFGF biological activity. ${ }^{7}$

In the current study, we analysed the $\mathrm{C}$ to $\mathrm{T}$ substitution at position 936 in the 3'-untranslated region of the VEGF gene, together with the $\mathrm{C}$ to $\mathrm{G}$ substitution at position -921 in the promoter region of the bFGF gene, in an attempt to reveal if their substitution is associated with susceptibility to NHL or agressiveness of the disease in Egyptian patients.

\section{PATIENTS and METHODS}

\section{Patients and Controls:}

The present study was conducted on 40 NHL patients (23 males and 17 females; aged 24-75 years, mean age 47.5 years). Patients were recruited from the Department of Oncology, Beni-Suef university hospital. Forty age and sex matched healthy individuals of both sexes served as controls. . Informed consents were obtained from patients and controls in advance. The study was approved by the Research Ethical Committee of Faculty of Medicine, Beni-Suef University and was conducted in accordance with the Helsinki Declaration of Human Rights. The patients' characteristics and clinical data are shown in Table 1.

VEGF and bFGF Genotyping: From each patient and control, $3-5 \mathrm{ml}$ of venous blood was collected on EDTA and stored at $-20^{\circ} \mathrm{C}$ until DNA extraction was done. The VEGF and bFGF alleles were detected using a polymerase chain reaction restriction fragment length polymorphism (PCR-

\begin{tabular}{|c|c|}
\hline Characteristics & $\begin{array}{l}\text { NHL patients }(n=40) \\
n(\%)\end{array}$ \\
\hline \multicolumn{2}{|l|}{ Sex } \\
\hline Female & $17(42.5)$ \\
\hline Male & $23(57.5)$ \\
\hline \multicolumn{2}{|l|}{ Age } \\
\hline$<60$ & $33(82.5)$ \\
\hline$>60$ & $7(17.5)$ \\
\hline \multicolumn{2}{|l|}{ Ann Arbor stage } \\
\hline |/II & $23(57.5)$ \\
\hline III/IV & $17(42.5)$ \\
\hline \multicolumn{2}{|l|}{ B symptoms } \\
\hline Absent & $14(35)$ \\
\hline Present & $26(65)$ \\
\hline \multicolumn{2}{|l|}{ Number of extranodal sites } \\
\hline$<2$ & $19(47.5)$ \\
\hline$>2$ & $21(52.5)$ \\
\hline \multicolumn{2}{|l|}{ Serum LDH } \\
\hline Normal & $27(67.5)$ \\
\hline Elevated & $13(32.5)$ \\
\hline \multicolumn{2}{|l|}{ Serum B2 microglobulin } \\
\hline Normal & $28(70)$ \\
\hline Increased & $12(30)$ \\
\hline \multicolumn{2}{|l|}{ Performance status (ECOG) } \\
\hline$<2$ & $21(52.5)$ \\
\hline$\geq 2$ & $19(37.5)$ \\
\hline \multicolumn{2}{|l|}{ IPI risk group } \\
\hline Low/low-intermediate ${ }^{1,2}$ & $28(70)$ \\
\hline Intermediate-high/high 3,4 & $12(30)$ \\
\hline \multicolumn{2}{|l|}{ Survival } \\
\hline Dead & $3(7.5)$ \\
\hline Alive & $37(92.5)$ \\
\hline \multicolumn{2}{|l|}{ Response to treatment } \\
\hline Complete remission & $14(35)$ \\
\hline Partial remission & $16(40)$ \\
\hline No response & $10(25)$ \\
\hline
\end{tabular}

RFLP). Amplification of both the VEGF gene; (rs3025039), and the bFGF gene promoter region; (rs308395) was done in the chosen PCR conditions. ${ }^{8}$ Then the PCR products were digested by the restriction endonucleases; N1aIII and BseNI specific for the VEGF and bFGF polymorphisms, respectively. The products were then analysed by electrophoresis on $2 \%$ agarose gel. For the VEGF genotyping, patients lacking the N1aIII site were considered homozygous for the $\mathrm{C}$ allele, moreover for the bFGF genotyping, patients lacking the BseNI site were considered homozygous for the bFGF C allele. Patients' genotype was detected according to their pattern of electrophoresis. Three 
electrophoretic patterns were encountered for each gene 1-VEGF: wild type CC, heterozygous $\mathrm{CT}$ and homozygous mutant TT, 2-bFGF: wild type CC, heterozygous $\mathrm{CG}$ and homozygous mutant $\mathrm{GG} .{ }^{7,8}$

\section{Statistical Analysis}

Data were coded and entered using the statistical package SPSS version 24. Data was summarized using mean and standard deviation for quantitative variables and frequencies (number of cases) and relative frequencies (percentages) for categorical variables. Comparisons between quantitative variables were done using unpaired T test. ${ }^{9}$ For comparing categorical data, Chi square $\left(\chi^{2}\right)$ test was performed. Exact test was used instead when the expected frequency is less than $5 .{ }^{10}$ Genotype and allele frequencies were calculated in the disease and the control groups. Odds ratio (OR) with $95 \%$ confidence intervals was calculated using logistic regression. ${ }^{11} \mathrm{P}$-values less than 0.05 were considered as statistically significant.

\section{RESULTS}

The mean age in our cases was $47.50 \pm 11.80$ years, while control group had a mean age of $38.47 \pm 10.31$ years. Different patient clinical and laboratory characteristics are listed in Table 1.

\section{Genotyping:}

The VEGF wild type (CC), heterozygous (CT) and homozygous (TT) were detected in $52.5 \%, 42.5 \%$ and $5 \%$ of NHL patients, respectively. The bFGF wild type (CC), heterozygous (CG) and homozygous (GG) were detected in $62.5 \%, 32.5 \%$ and $5 \%$ respectively. The frequencies of different genotypes in both genes among cases and controls are shown in Table 2.

\section{VEGF gene:}

Comparing the different genotypes, in both the group of patients and healthy subjects, showed that the VEGF gene polymorphism was associated with NHL susceptibility, as the mutant VEGF was significantly higher among NHL patients with more than double susceptibility to the disease than individuals not carrying the polymorphism ( $\mathrm{OR}=$ 2.714, $\mathrm{p}=0.039$ ).

\begin{tabular}{|llll|}
\hline \multicolumn{3}{|l|}{ Table 2. Distribution of the VEGF and bFGF genotypes in } \\
patients with NHL patients and controls
\end{tabular}

The VEGF heterozygous genotype CT showed significant susceptibility to NHL $(\mathrm{OR}=2.698, \mathrm{p}=$ 0.047 ), while the homozygous genotype didn't express statistical difference $(\mathrm{OR}=2.857, \mathrm{p}=0.404)$. The mutant $\mathrm{T}$ allele showed a higher frequency in patients $(26.2 \%)$ than controls $(13.8 \%)$ but it wasn't statistically significant $(\mathrm{OR}=2.233, \mathrm{p}=$ 0.051) Table 3.

In 26 patients who suffered from B symptoms 18 (94.7\%) had statistically higher carriers of VEGF polymorphic T allele versus $8(38.1 \%)$ who didn't $(\mathrm{p}<0.001)$.

\section{bFGF gene:}

Mutant bFGF genotypes frequency whether heterozygous or homozygous didn't show statistical difference when comparing patients and controls $(\mathrm{p}=0.203, \mathrm{p}=0.860)$.

Moreover it is worth noting that, the frequency of the polymorphic alleles of the bFGF (G) was higher in NHL patients $(21.2 \%)$ versus $15 \%$ in control group, but this difference didn't reach statistical significance $(\mathrm{OR}=1.529, \mathrm{p}=0.307)$ Table 3 .

Analysis of combined genotype presentation, significant susceptibility to NHL was detected among patients carrying the heterozygous genotype of both genes $(\mathrm{CT}+\mathrm{CG}),(\mathrm{OR}=6.00, \mathrm{p}=0.039)$ Table 4 .

On the other hand there was no significant difference between patients with wild and mutant genotype of bFGF regarding the presence of B symptoms $(\mathrm{p}=0.123)$

Patients carrying mutant forms of bFGF had significantly higher susceptibility to aggressive NHL compared to those with indolent disease $(\mathrm{p}=0.010$, 
International Journal of Hematology and Oncology

Table 3. Comparison of VEGF and bFGF genotypes and allelic distribution in NHL patients and controls

\begin{tabular}{|c|c|c|c|c|c|c|c|c|c|}
\hline & & \multicolumn{2}{|c|}{ Patients } & \multicolumn{2}{|c|}{ Controls } & \multirow[b]{2}{*}{ p } & \multirow[b]{2}{*}{ OR } & \multicolumn{2}{|c|}{$95 \% \mathrm{Cl}$} \\
\hline & & Count & $\%$ & Count & $\%$ & & & Lower & Upper \\
\hline \multirow[t]{6}{*}{ VEGF } & $\mathrm{CC}$ & 21 & $52.5 \%$ & 30 & $75.0 \%$ & Reference & & & \\
\hline & CT & 17 & $42.5 \%$ & 9 & $22.5 \%$ & 0.047 & 2.698 & 1.011 & 7.202 \\
\hline & $\pi$ & 2 & $5 \%$ & 1 & $2.5 \%$ & 0.404 & 2.857 & 0.243 & 33.589 \\
\hline & $\mathrm{CT}+\mathrm{TT}$ & 19 & $47.5 \%$ & 10 & $25 \%$ & 0.039 & 2.17 & 1.053 & 6.999 \\
\hline & Allele C & 59 & 73.8 & 69 & $86.2 \%$ & Reference & & & \\
\hline & Allele T & 21 & 26.2 & 11 & $13.8 \%$ & 0.051 & 2.233 & 0.995 & 5.009 \\
\hline \multirow[t]{6}{*}{ bFGF } & $\mathrm{CC}$ & 25 & $62.5 \%$ & 30 & $75.0 \%$ & Reference & & & \\
\hline & $\mathrm{CT}$ & 13 & $32.5 \%$ & 8 & $20.0 \%$ & 0.203 & 1.950 & 0.697 & 5.543 \\
\hline & $\mathrm{GG}$ & 2 & $5.0 \%$ & 2 & $5.0 \%$ & 0.860 & 1.200 & 0.158 & 9.142 \\
\hline & $\mathrm{CG}+\mathrm{GG}$ & 15 & $37.5 \%$ & 10 & $25.0 \%$ & 0.230 & 1.800 & 0.689 & 4.702 \\
\hline & Allele C & 63 & $78.8 \%$ & 68 & $85.0 \%$ & Reference & & & \\
\hline & Allele G & 17 & $21.2 \%$ & 12 & $15.0 \%$ & 0.307 & 1.529 & 0.677 & 3.453 \\
\hline
\end{tabular}

OR 17.818), and the same relationship was detected on comparing to normal controls $(\mathrm{p}=0.014$, OR 3.818) Table 5.

Patients characterized by IPI 3 and/or 4 were more frequently carrying the VEGF polymorphism $(100 \%)$ compared with patients with IPI 1and /or $2(25 \%)$. Moreover, the polymorphic bFGF was more frequent among patients with IPI 3 and/or 4 $(33.3 \%)$ than controls $(25 \%)$, but neither of these differences reached statistical significance $(p=$ 0.998 and 0.722 respectively) Table 6 .

The distribution of the VEGF alleles among patients who didn't respond to treatment was significantly higher $(42.1 \%)$ than patients in complete or partial remission when compared to responders who showed $(0 \%)$ VEGF mutation $(\mathrm{p}=0.017)$.ver- sus responders. But there was no significant difference between wild and mutant bFGF regarding the response to treatment $(\mathrm{p}=0.604)$. Analysis of the distribution of VEGF and bFGF genotypes with respect to the age and stage was done and didn't show statistical significance.

\section{DISCUSSION}

Non Hodgkin Lymphomas are a heterogenous group of lymphoproliferative neoplasms with different presenting features, clinical course and response to treatment. In Egypt the National cancer Institute reported that NHLs are the third most common cancer in Egyptian men and the second in women. ${ }^{12}$

\begin{tabular}{|c|c|c|c|c|c|c|c|c|}
\hline & \multicolumn{2}{|c|}{ Patients } & \multicolumn{2}{|c|}{ Controls } & \multirow[b]{2}{*}{$p$} & \multirow[b]{2}{*}{ OR } & \multicolumn{2}{|l|}{$95 \% \mathrm{Cl}$} \\
\hline & Count & $\%$ & Count & $\%$ & & & Lower & Upper \\
\hline $\mathrm{VEGF}=\mathrm{CC}$ and $\mathrm{bFGF}=\mathrm{CC}$ & 14 & $35.0 \%$ & 24 & $60.0 \%$ & Reference & & & \\
\hline $\mathrm{VEGF}=\mathrm{CC}$ and $\mathrm{bFGF}=\mathrm{CG}$ & 6 & $15.0 \%$ & 6 & $15.0 \%$ & 0.420 & 1.714 & 0.463 & 6.351 \\
\hline $\mathrm{VEGF}=\mathrm{CC}$ and $\mathrm{bFGF}=\mathrm{GG}$ & 1 & $2.5 \%$ & 0 & $0.0 \%$ & 1.000 & ---- & ---- & ----- \\
\hline VEGF $=C T$ and $b F G F=C C$ & 9 & $22.5 \%$ & 6 & $15.0 \%$ & 0.131 & 2.571 & 0.755 & 8.757 \\
\hline $\mathrm{VEGF}=\mathrm{CT}$ and $\mathrm{bFGF}=\mathrm{CG}$ & 7 & $17.5 \%$ & 2 & $5.0 \%$ & 0.039 & 6.000 & 1.092 & 32.979 \\
\hline $\mathrm{VEGF}=\mathrm{CT}$ and $\mathrm{bFGF}=\mathrm{GG}$ & 1 & $2.5 \%$ & 1 & $2.5 \%$ & 0.711 & 1.714 & 0.099 & 29.610 \\
\hline $\mathrm{VEGF}=T \mathrm{~T}$ and $\mathrm{bFGF}=\mathrm{CC}$ & 2 & $5.0 \%$ & 0 & $0.0 \%$ & 0.999 & ---- & ---- & ----- \\
\hline
\end{tabular}


International Journal of Hematology and Oncology

\begin{tabular}{|c|c|c|c|c|c|c|c|c|c|}
\hline & & \multicolumn{2}{|c|}{ Patients } & \multicolumn{2}{|c|}{ Controls } & \multirow[b]{2}{*}{$\mathbf{p}$} & \multirow[b]{2}{*}{ OR } & \multicolumn{2}{|l|}{$95 \% \mathrm{Cl}$} \\
\hline & & Count & $\%$ & Count & $\%$ & & & Lower & Upper \\
\hline \multirow[t]{4}{*}{ VEGF } & $\mathrm{CC}$ & 13 & $52.0 \%$ & 8 & $53.3 \%$ & Reference & & & \\
\hline & $\mathrm{CT}$ & 11 & $44.0 \%$ & 6 & $40.0 \%$ & 0.859 & 1.128 & 0.299 & 4.260 \\
\hline & $\pi$ & 1 & $4.0 \%$ & 1 & $6.7 \%$ & 0.744 & 0.615 & 0.034 & 11.278 \\
\hline & $\mathrm{CT}+\mathrm{TT}$ & 12 & $48.0 \%$ & 7 & $46.7 \%$ & 0.935 & 1.055 & 0.293 & 3.803 \\
\hline \multirow[t]{4}{*}{ bFGF } & $\mathrm{CC}$ & 11 & $44.0 \%$ & 14 & $93.3 \%$ & Reference & & & \\
\hline & $C G$ & 13 & $52.0 \%$ & 0 & $0.0 \%$ & 0.998 & ---- & ---- & ---- \\
\hline & $G G$ & 1 & $4.0 \%$ & 1 & $6.7 \%$ & 0.870 & 1.273 & .071 & 22.720 \\
\hline & $\mathrm{CG}+\mathrm{GG}$ & 14 & $56.0 \%$ & 1 & $6.7 \%$ & 0.010 & 17.818 & 2.020 & 157.158 \\
\hline
\end{tabular}

The etiology of NHLs has not been fully elucidatedhowever, there is evolving evidence suggesting that formation of new blood vessels contributes to the progression of haematological malignancies..$^{13,14}$ An important proangiogenic agent is VEGF, acting as a potent mediator of angiogenesis influencing proliferation, survival and tumour vascularisation. Another agent is the bFGF which plays an important role in vascular response by increasing endothelial cell proliferation, stimulating migration, and promoting angiogenesis. ${ }^{8}$ This explains why the analysis of VEGF and bFGF genes in haematological malignancies has been recently attracting researchers' attention. ${ }^{3,8,15}$

In our study the distribution of The VEGF and bFGF genotypes and alleles were analyzed in NHL patients and controls; The VEGF genotypes CC, $\mathrm{CT}$ and TT were detected in $52.5 \%, 42.5 \%$ and
$5 \%$ of NHL patients respectively. The bFGF CC, CG and GG were detected in $62.5 \%, 32.5 \%$ and $5 \%$ respectively. In a study done by Wrobel and colleagues $^{8}$ on 78 NHL patients and 122 healthy controls, the reportedgenotype distribution was in agreement with our results; except that none of their patients presented with homozygous mutated genotype of VEGF or bFGF while it was least presented among our patients (5\%). Also the allelic frequencies in our control group were in accordance with other studies as Galimberti et al. ${ }^{16}$, Kariz et al. ${ }^{17}$ and Petrovic et al. ${ }^{18}$

In the current study, individuals carrying the VEGF gene polymorphism were over two times more likely to develop NHL $(\mathrm{OR}=2.714, \mathrm{p}=0.039)$. This relation wasn't recorded by Wrobel et al. [8] who found no significant association between VEGF gene polymorphism and susceptibility to NHL. On

\begin{tabular}{|c|c|c|c|c|c|c|c|c|c|}
\hline & & \multicolumn{2}{|c|}{$\begin{array}{l}\text { Intermediate } \\
\text { high/high }(3,4)\end{array}$} & \multicolumn{2}{|c|}{$\begin{array}{l}\text { Low/low } \\
\text { Intirmediat }(1,2)\end{array}$} & \multirow[b]{2}{*}{$p$} & \multirow[b]{2}{*}{ OR } & \multicolumn{2}{|l|}{$95 \% \mathrm{Cl}$} \\
\hline & & $n=12$ & $\%$ & $n=28$ & $\%$ & & & Lower & Upper \\
\hline \multirow[t]{4}{*}{ VEGF } & $\mathrm{CC}$ & 0 & $0.0 \%$ & 21 & $75.0 \%$ & Reference & & & \\
\hline & CT & 12 & $100.0 \%$ & 5 & $17.9 \%$ & 0.998 & ---- & ---- & ---- \\
\hline & $\pi$ & 0 & $0.0 \%$ & 2 & $7.1 \%$ & 1.000 & ---- & ---- & ---- \\
\hline & $\mathrm{CT}+\mathrm{TT}$ & 12 & $100.0 \%$ & 7 & $25.0 \%$ & 0.998 & ---- & ---- & ---- \\
\hline \multirow[t]{4}{*}{ bFGF } & $\mathrm{CC}$ & 8 & $66.7 \%$ & 17 & $60.7 \%$ & Reference & & & \\
\hline & $C G$ & 3 & $25.0 \%$ & 10 & $35.7 \%$ & 0.567 & 0.638 & 0.137 & 2.973 \\
\hline & GG & 1 & $8.3 \%$ & 1 & $3.6 \%$ & 0.610 & 2.125 & 0.117 & 38.481 \\
\hline & $\mathrm{CG}+\mathrm{GG}$ & 4 & $33.3 \%$ & 11 & $39.3 \%$ & 0.722 & 0.773 & 0.187 & 3.196 \\
\hline
\end{tabular}


the other hand the presence of VEGF T allele was higher among patients than controls in both Wrobel and colleagues ${ }^{8}$ patients and our patients but it didn't reach statistical significance $(p=0.051)$.

The results of the present study observed that patients with VEGF polymorphic features were more frequently presented with a higher IPI score when compared to both patients with low or intermediate IPI score and controls. This relationship didn't show statistical significance $(\mathrm{p}=0.998)$. The same tendency of individuals carrying the VEGF T variant were over three times more likely to develop NHL was reported by Wrobel et al. ${ }^{8}$

Few studies reported the role of polymorphic features in the genes coding for these two proangiogenic agents. A Chinese study on VEGF polymorphism analysed DNA samples of 431 NHL patients using Restriction fragment length polymorphism ${ }^{19}$, reported that none of the studied genotypes were significantly associated with gender, age, tumour size, B symptoms or immunohistological subtype. In contrast, our study revealed a significantly higher $(p=0.001)$ presence of B symptoms in patients carrying mutant VEGF.

Most of the studies published to date have detected the relationship of polymorphisms in the promoter region of the $b$ FGF gene with proliferative diabetic retinopathy ${ }^{18}$ and myocardial infarction ${ }^{17}$ in patients with type 2 diabetes.

Wrobel et al. ${ }^{8}$, was the first study to describe the association of bFGF polymorphism and NHL. They detected a previously unreported association between bFGF gene polymorphism and a more unfavourable course of the disease. This strong tendency to aggressive NHL was detected in our work in patients carrying mutant forms of bFGF who showed more susceptibility to aggressive NHL compared to those with indolent disease $(\mathrm{p}=$ $0.010, \mathrm{OR}=17.818)$. These results were supported byWrobel et al. ${ }^{8}$, who reported that aggressive NHL patients were more than twice as frequently presented with the bFGF G variant as those with the indolent histological type.

Other studies detected SNP (single nucleotide polymorphism) mediated missense mutations at various positions of FGFR that significantly con- tributed to alterations in FGFR activity with a corresponding increase in tumorigenesis. ${ }^{20}$ In their investigation of the FGFR genotype in more than 400 NHL patients, both Cha et al. ${ }^{21}$, and Gao et al. ${ }^{22}$, they reported significantly higher mutant genotype among NHL patients than controls.

In the present study the analysis of mutant bFGF genotypes revealed higher frequency among patients than controls but did not show a statistical difference $(p=0.230)$. These results are in agreement with Cha et al. ${ }^{21}$, and Gao et al. ${ }^{22}$ Moreover it is worth noting that, the frequency of the polymorphic $\mathrm{G}$ alleles of bFGF was higher in NHL patients (21.2\%) compared to $15 \%$ in control group, but this difference did not reach a statistical significance $(\mathrm{OR}=1.529, \mathrm{p}=0.307)$.

The present study showed significantly higher polymorphic forms of VEGF alleles among non responders to treatment than those in remission $(\mathrm{p}=$ $0.017)$. This relation was not reported in previous studies Diao et al. ${ }^{19}$, who did not report an association of VEGF genotype and response to treatment. They also stated it was not significantly associated with gender, age, tumour size or immunohistological type. These findings were in agreement with our results except for the histological subtypes, where patients with mutant $\mathrm{G}$ allele of bFGF had significantly higher susceptibility to aggressive NHL compared to those with indolent disease and normal controls respectively $(\mathrm{p}=0.010, \mathrm{OR}=$ 17.818), $(\mathrm{p}=0.014, \mathrm{OR}=3.818)$.

Enhanced angiogenesis may explain our findings of VEGF and bFGF mutant association with NHL especially the aggressive subtypes. Many studies correlated the serum levels and genotype of VEGF and bFGF and the and their NHL disease course and its prognosis.

This study could not detect the association between serum levels of VEGF and bFGF and the course of the disease due to limitation of sample size.This limitation could be a draw back in the study, but it will be taken asa future step to a broader study including larger number of both patients and healthy controls. 


\section{Acknowledgment:}

The authors would like to express their deepest gratitude for Professor Seham Omar, Professor of Clinical Pathology, Faculty of Medicine, BeniSuef University for her consistent help and support throughout the work.

\section{REFERENCES}

1. Ribatti $D$, Vacca A, Nico B, et al. Angiogenesis spectrum in the stroma of Bcell non -Hodgkin's lymphomas. An immunohistochemical and ultrastructural study. Eur J Haematol 56: 45-53, 1996.

2. Hazar B, Paydas S, Zorludemir S, et al. Prognostic significance of microvessel density and vascular endothelial growth factor (VEGF) expression in non-Hodgkin's lymphoma. Leuk Lymphoma 44: 2089-2093, 2003.

3. Vincenti V, Cassano C, Rocchi M, Persico M. Assignment of the vascular endothelial growth factor gene to human chromosome 6p21.3. Circulation 93: 1493-1495, 1996.

4. Brogan I, Khan N, Isaac K, et al. Novel polymorphisms in the promoter and 5' UTR regions of the human vascular endothelial growth factor gene. Hum Immunol 60: 1245-1249, 1999.

5. Awata $\mathrm{T}$, Inoue $\mathrm{K}$, Kurihara $\mathrm{S}$, et al. A common polymorphism in the 5'-untranslated region of the VEGF gene is associated with diabetic retinopathy in type 2 diabetes. Diabetes 51: 1635-1639, 2002.

6. Lafage-Pochitaloff M, Galland F, Simonetti J, et al. The human basic fibroblast growth factor gene is located on the long arm of chromosome 4 at bands q26-q27. Oncogene Res 5: 241-244, 1990.

7. Ber'anek M, Tschooplov'a S, Kankováa K, et al. Genetic variation in the promoter region of the basic fibroblast growth factor gene, Hum Immunol 64: 374-377, 2003.

8. Wrobel T, Mazur G, Dzietczenia J, et al. VEGF and bFGF gene polymorphisms in patients with non-Hodgkin's lymphoma. Biomed Res Int 2013: 159813, 2013.

9. Chan YH. Biostatistics102: Quantitative Data-Parametric \& Non-parametric Tests. Singapore Med J 44: 391-396, 2003.

10. Chan YH. Biostatistics 103: Qualitative Data -Tests of Independence. Singapore Med J 44: 498-503, 2003.

11. Chan YH. Biostatistics 202: logistic regression analysis. Singapore Med J 45: 149-153, 2004.

12. El-Sayed L, Ghoneim H, Abdel Rahman M, et al. Prognostic value of FOXP3 and TGF-b expression in both peripheral blood and lymph nodes in patients with B-non Hodgkin's lymphoma. Alex J Med 7: 253-265, 2013.

13. Paydas S, Seydaoglu G, Ergin M, et al. The prognostic significance of VEGF-C and VEGF-A in non-Hodgkin lymphomas. Leuk Lymphoma 50: 366-373, 2009.
14. Klein S, Roghani M, Rifkin DB. Fibroblast growth factors as angiogenesis factors: new insights into their mechanism of action. EXS 79: 159-192, 1997.

15. Jorgensen JM, Sorensen FB, Bendix K, et al. Expression level, tissue distribution pattern, and prognostic impact of vascular endothelial growth factors VEGF and VEGF-C and their receptors Flt-1, KDR, and Flt-4 in different subtypes of non-Hodgkin lymphomas. Leuk Lymphoma 50:1647-1660, 2009.

16. Galimberti S, Nagy B, Palumbo GA, et al. Vascular endothelial growth factor polymorphisms in mantle cell lymphoma. Acta Haematol 123: 91-95, 2010.

17. Karĩz S, Grabar D, Krkovĩc M, et al. Polymorphisms in the promoter region of the basic fibroblast growth factor gene are not associated with myocardial infarction in a slovene population with type 2 diabetes. J Int Med Res 37: 1596-1603, 2009.

18. Petrovĩc MG, Krkovĩc M, Osredkar J, et al. Polymorphisms in the promoter region of the basic fibroblast growth factor gene and proliferative diabetic retinopathy in Caucasians with type 2 diabetes. Clin Exper Ophthalmol 36: 168-172, 2008.

19. Diao LP, Yu XM, Gao YH, et al. Association of VEGF genetic polymorphisms with the clinical characteristics of non-Hodgkin's lymphoma. J Cancer Res Clin Oncol 135: 1473-1481, 2009.

20. Feng S, Zhou L, Nice E C, Huang C. Fibroblast growth factor receptors: multifactorial-contributors to tumour initiation and progression. Histol Histopathol 30: 13-31, 2015.

21. Cha Z, Zang Y, Guo H, et al. Fibroblast growth factor receptor 4 polymorphisms and the prognosis of $\mathrm{NHL}$. Mol Biol Rep 41: 1165-1170, 2014.

22. Gao L, Feng Z, Li Q, et al. Fibroblast growth factor receptor 4 polymorphism is associated with increased risk and poor prognosis of non hodgkin's lymphoma. Tumour Biol 35: 2997-3002, 2014.

\section{Correspondence:}

Dr. Dina EI DAHSHAN

Beni-Suef University, Faculty of Medicine

Department of Clinical Pathology

BENI-SUEF / EGYPT

Tel: +201001002425

e-mail: dina.eldahshan@med.bsu.edu.eg dina.eldahshan@gmail.com 